\title{
Mortality of New York children with sickle cell disease identified through newborn screening
}

\author{
Ying Wang, PhD, MPH',2, Gang Liu, MS', Michele Caggana, ScD ${ }^{1,3}$, Joseph Kennedy, $\mathrm{MPH}^{4}$, \\ Regina Zimmerman, $\mathrm{PhD}^{4}$, Suzette O. Oyeku, MD, MPH ${ }^{5}$, Ellen M. Werner, MA, PhD ${ }^{6}$, \\ Althea M. Grant, $\mathrm{PhD}^{7}$, Nancy S. Green, $\mathrm{MD}^{8}$ and Scott D. Grosse, $\mathrm{PhD}^{7}$
}

\begin{abstract}
Purpose: Long-term follow-up of newborn screening for conditions such as sickle cell disease can be conducted using linkages to population-based data. We sought to estimate childhood sickle cell disease mortality and risk factors among a statewide birth cohort with sickle cell disease identified through newborn screening.
\end{abstract}

Methods: Children with sickle cell disease identified by newborn screening and born to New York residents in 2000-2008 were matched to birth and death certificates. Mortality rates were calculated (using numbers of deaths and observed person-years at risk) and compared with mortality rates for all New York children by maternal race/ethnicity. Stratified analyses were conducted to examine associations between selected factors and mortality.

Results: Among 1,911 infants with sickle cell disease matched to birth certificates, 21 deaths were identified. All-cause mortality following diagnosis was 3.8 per 1,000 person-years in the first 2 years of life and 1.0 per 1,000 person-years at ages $2-9$ years. The mortality

\section{INTRODUCTION}

In the United States, 80,000-100,000 people, primarily of African ancestry, have sickle cell disease (SCD)..$^{1-3}$ Based on national newborn screening (NBS) records, the frequency of SCD is $\sim 1$ in 360 live births among African Americans and 1 in 16,300 live births among Hispanics. ${ }^{4}$ In New York, the estimated incidence is 1 in 230 newborns born to non-Hispanic black mothers and 1 in 2,320 newborns born to Hispanic mothers. ${ }^{5}$

People with SCD are at risk of life-threatening complications and organ damage, reducing quality of life and life expectancy.,6 Before the 1980s, mortality among US children with SCD was high primarily due to infections. ${ }^{7}$ Median age at death attributed to sickle cell anemia in 1967 was roughly 20 years. ${ }^{8}$ Subsequent improvements in life span and reduced childhood mortality ${ }^{9-16}$ reflect multiple interventions, including early diagnosis by NBS, ${ }^{17-19}$ parental education, ${ }^{20}$ and standardized preventive and therapeutic approaches, in particular penicillin prophylaxis, ${ }^{21}$ hydroxyurea, ${ }^{22-24}$ and pneumococcal immunization. ${ }^{25}$ rate was significantly lower among children of foreign-born mothers and was significantly higher among preterm infants with low birth weight. The mortality rates were not significantly higher for infants after 28 days with sickle cell disease than for all New York births, but they were 2.7-8.4 times higher for children 1 through 9 years old with homozygous sickle cell disease than for those of all non-Hispanic black or Hispanic children born to New York residents.

Conclusion: Estimated mortality risk in children with homozygous sickle cell disease remains elevated even after adjustment for maternal race/ethnicity. These results provide evidence regarding the current burden of child mortality among children with sickle cell disease despite newborn screening.

Genet Med advance online publication 25 September 2014

Key Words: long-term follow-up; maternal race/ethnicity; mortality; newborn screening; sickle cell disease
Long-term follow-up (LTFU) of children with inherited disorders identified by NBS is essential to ensure the timely receipt of disease-modifying interventions in a medical home and to track the health status and health-care utilization of affected children. ${ }^{26}$ The Centers for Disease Control and Prevention funded four states to conduct LTFU through 3 years of age for children with metabolic disorders detected through NBS. ${ }^{27}$ Various methods have been used to collect and analyze data on health-care utilization and health outcomes for children identified through NBS. ${ }^{27,28}$ Studies showed that the use of linked population-based administrative data sources is a feasible and relatively inexpensive method to conduct LTFU. ${ }^{28,29}$

In 2010, the New York State Department of Health and six other state health departments were awarded funds by the Centers for Disease Control and Prevention and the National Heart, Lung and Blood Institute/National Institutes of Health to develop a pilot population-based statewide surveillance system for SCD and thalassemia. ${ }^{30}$ The objectives of this

\footnotetext{
${ }^{1}$ School of Public Health, University at Albany, State University of New York, Albany, New York, USA; ${ }^{2}$ Division of Data Management and Research, Office of Primary Care and Health Management System, New York State Department of Health, Albany, New York, USA; ${ }^{3}$ Newborn Screening Program, Wadsworth Center, New York State Department of Health, Albany, New York, USA; ${ }^{4}$ Office of Vital Statistics, New York City Department of Health and Mental Hygiene, New York, New York, USA; ${ }^{5}$ Department of Pediatrics, Albert Einstein College of Medicine/Children's Hospital Montefiore, New York, New York, USA; ${ }^{6}$ Division of Blood Diseases and Resources, National Heart, Lung and Blood Institute, Bethesda, Maryland, USA; ${ }^{7}$ Division of Blood Disorders, National Center on Birth Defects and Developmental Disabilities, Centers for Disease Control and Prevention, Atlanta, Georgia, USA; ${ }^{8}$ Department of Pediatrics, Columbia University Medical Center, New York, New York, USA. Correspondence: Ying Wang (wxy01@health.state.ny.us)
} 
study were to conduct LTFU of children with SCD identified through NBS by linking the children with vital records data, to estimate childhood SCD mortality, and to identify mortality risk factors.

\section{SCD cases}

\section{MATERIALS AND METHODS}

The study cohort contains children with confirmed diagnoses of SCD-identified by the New York State Department of Health NBS program ${ }^{31}$-born to New York residents in 2000-2008. SCD types included hemoglobin $\mathrm{S}$ disease (HbSS), sicklehemoglobin $\mathrm{C}$ disease $(\mathrm{HbSC})$, sickle $\beta^{0}$ thalassemia $\left(\mathrm{HbS} \beta^{\circ}\right)$, sickle $\beta^{+}$thalassemia, and other less common forms of SCD. DNA testing is not performed by the NBS program, and hence the children with HbSS cannot be definitively distinguished from those with $\mathrm{HbS}^{0}$. More than $96 \%$ of cases of SCD in New York involved $\mathrm{HbSS}, \mathrm{HbS}^{\circ}$, or $\mathrm{HbSC}$. Children born outside of New York were not included in this analysis.

\section{Vital records}

The Bureau of Biometrics and Health Statistics of the New York State Department of Health and the Office of Vital Statistics of the New York City Department of Health and Mental Hygiene provided birth and death certificate data for New York residents following approval by the institutional review boards of both agencies. Birth certificates include clinical data (birth weight and gestational age) and demographic data (maternal race/ ethnicity and country of birth); death certificates include the child's age and cause of death.

\section{Data matching}

The SCD cases were matched to birth records to obtain demographic and clinical information; the SCD cases were matched to death records to identify deaths, using deterministic data linkage methods, as described elsewhere. ${ }^{5}$

\section{Deaths}

Deaths among the study cohort during the years 2000-2009 were ascertained from the death certificates. The longest followup period was 10 years, for children born in 2000, whereas the shortest follow-up period was 1 year, for those born in 2008. Date of death and causes of death were obtained from death certificates. Deaths were presumed to be related to SCD if an SCD diagnosis (International Classification of Diseases, 10th revision, codes D57.0, D57.1, D57.2, D57.4, or D57.8) was listed on the death certificate and no unrelated cause of death was listed. Records were reviewed by two coauthors (N.S.G., S.D.G.), who followed a similar approach used in a previous study to categorize deaths as potentially related to SCD or unrelated to SCD. The coauthors classified deaths with perinatal conditions, birth defects, autoimmune disorders, or other causes not associated with the clinical course of SCD as unrelated to SCD. ${ }^{13}$ The primary and secondary causes of death for children born with SCD but for whom SCD was not listed on the death certificate were similarly reviewed.

\section{Statistical analysis}

Mortality rate was calculated as the number of deaths divided by total person-years at risk. Person-years at risk were calculated using date of birth and date of death for deceased cases. For children who were alive at the end of the study, person-years at risk were calculated using date of birth and the end date of the study (31 December 2009). Mortality rates were calculated by SCD type and by selected demographic and clinical risk factors, including the child's sex, birth weight, and gestational age, as well as maternal age, race/ethnicity, country of birth, and residence at delivery (either New York City or New York State excluding New York City).

To compare child ( $\leq 9$ years old) mortality for children with SCD and all live births (with or without SCD), the ratios of mortality rates were calculated after excluding deaths during the first 28 days of life. The comparative analysis excluded neonatal ( $<28$ days) deaths because deaths of infants with SCD who died before the collection of dried blood spots or before the infant completed the screening and diagnostic process were not included among SCD deaths. Owing to limited access to vital records for the study period, we were not able to match all live births in 2000-2008 to the death certificate files to estimate the mortality rate restricted to children born without SCD.

The Poisson exact test for modeling rare events with persontime data was used to examine the relative risk (mortality rate ratio) and 95\% confidence interval for selected demographic factors. A $P$ value $<0.05$ was chosen to indicate that the mortality rates between comparison groups are statistically significantly different; no adjustment was made for multiple comparisons. The SAS software package, version 9.2 (SAS Institute, Cary, NC) was used for summary statistics and regression analysis.

\section{RESULTS}

A total of 1,911 newborns with SCD identified through NBS were matched to birth certificates from among $\sim 2.2$ million New York live births during the years 2000-2008. Twenty-one deaths $(1.1 \%)$ subsequent to a diagnosis of SCD were identified during the follow-up period of 2000-2009. The numbers of SCD cases, deaths, person-years at risk, mortality rates, and median age at death by selected demographic and clinical factors and by age group are presented in Table 1 . The overall mortality rate was 2.0 per 1,000 person-years for all SCD cases, 2.5 per 1,000 for HbSS and $\mathrm{HbS} \beta^{\circ}$ cases, and 1.4 per 1,000 personyears for HbSC cases. No deaths were found among children with other types of SCD. Statistically significantly higher overall mortality rates were found among low-birth-weight (LBW) children compared with normal-birth-weight children (5.5 vs. 1.6 per 1,000 person-years; $P=0.02$ ) and children of US-born mothers compared with children of foreign-born mothers (3.1 vs. 1.2 per 1,000 person-years; $P=0.05$ ).

By age group, the mortality rate was 3.8 per 1,000 personyears among children 0 to $<2$ years old and 1.0 per 1,000 person-years among children $2-9$ years old. The highest mortality rates were found among infants 0 to $<1$ year old (4.2 per 1,000 person-years), with a median age at death of 3.4 months, and 


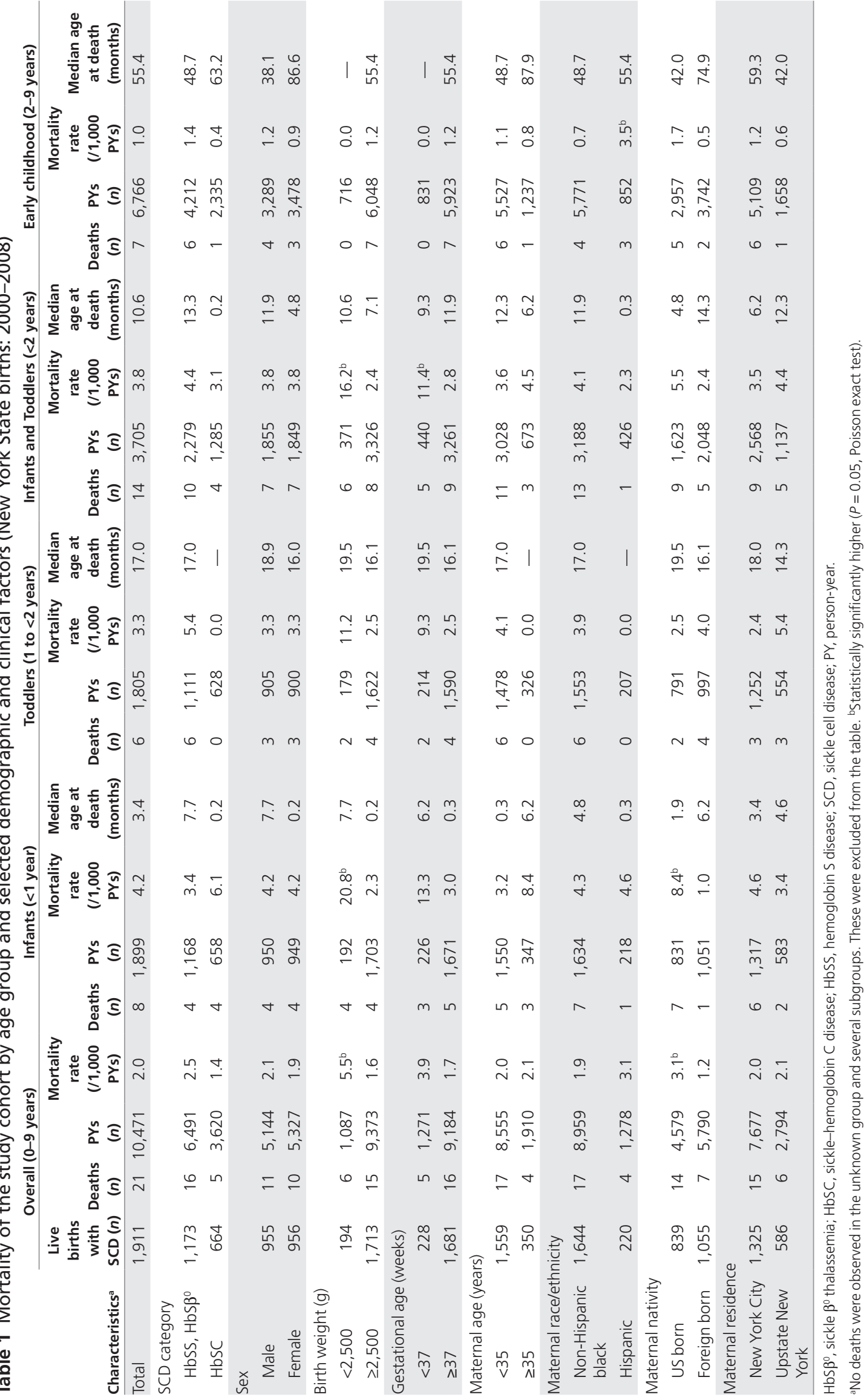


Table 2 Postneonatal ( $\geq 28$ days) all-cause mortality rate ratios and $95 \%$ confidence intervals (Cls) by sickle cell disease (SCD) type and demographic and clinical characteristics as compared with all live births (New York State Birth Cohort, 2000-2008)

\begin{tabular}{|c|c|c|c|c|c|c|c|c|c|c|}
\hline \multirow[b]{2}{*}{ Characteristics } & \multirow[b]{2}{*}{$\begin{array}{l}\text { Live birth } \\
\text { mortality rate } \\
\text { (/1,000 PYs) }\end{array}$} & \multicolumn{3}{|c|}{ Total SCD } & \multicolumn{3}{|c|}{$\mathrm{HbSS}, \mathrm{HbS} \beta^{0}$} & \multicolumn{3}{|c|}{$\mathrm{HbSC}$} \\
\hline & & $\begin{array}{c}\text { Mortality } \\
\text { rate } \\
\text { (/1,000 PYs) }\end{array}$ & $\begin{array}{l}\text { Rate } \\
\text { ratio }\end{array}$ & $95 \% \mathrm{Cl}$ & $\begin{array}{l}\text { Mortality } \\
\text { rate } \\
\text { (/1,000 PYs) }\end{array}$ & $\begin{array}{l}\text { Rate } \\
\text { ratio }\end{array}$ & $95 \% \mathrm{Cl}$ & $\begin{array}{c}\text { Mortality } \\
\text { rate } \\
\text { (/1,000 PYs) }\end{array}$ & $\begin{array}{l}\text { Rate } \\
\text { ratio }\end{array}$ & $95 \% \mathrm{Cl}$ \\
\hline \multicolumn{11}{|l|}{ Sex } \\
\hline Male & 0.41 & 2.17 & 5.3 & $2.6-9.5$ & 2.82 & 6.9 & $3.1-13.1$ & 1.15 & 2.8 & $0.3-10.2$ \\
\hline Female & 0.57 & 1.33 & 2.3 & $0.9-4.8$ & 2.18 & 3.8 & $1.5-7.9$ & No deaths & & \\
\hline 28 days $-<1$ years & 1.95 & 2.84 & 1.5 & $0.5-3.4$ & 3.70 & 1.9 & $0.5-4.9$ & 1.64 & 0.8 & $0.0-4.7$ \\
\hline $1-<2$ years & 0.33 & 3.32 & 10.0 & $3.6-21.8$ & 5.40 & 16.2 & $5.9-35.4$ & No deaths & & \\
\hline$\geq 2$ years & 0.15 & 1.03 & 7.0 & $2.8-14.4$ & 1.42 & 9.6 & $3.5-20.9$ & 0.43 & 2.9 & $0.1-16.1$ \\
\hline \multicolumn{11}{|l|}{ Maternal race/ethnicity } \\
\hline Non-Hispanic black & 0.91 & 1.70 & 1.9 & $1.0-3.1$ & 2.43 & 2.7 & $1.4-4.6$ & 0.63 & 0.7 & $0.1-2.5$ \\
\hline Upstate New York & 0.48 & 1.82 & 3.8 & $1.2-8.8$ & 3.17 & 6.6 & $2.1-15.4$ & No deaths & & \\
\hline
\end{tabular}

$\mathrm{HbS} \beta^{\circ}$, sickle $\beta^{0}$ thalassemia; HbSC, sickle-hemoglobin C disease; HbSS, hemoglobin S disease; PYs, person-years.
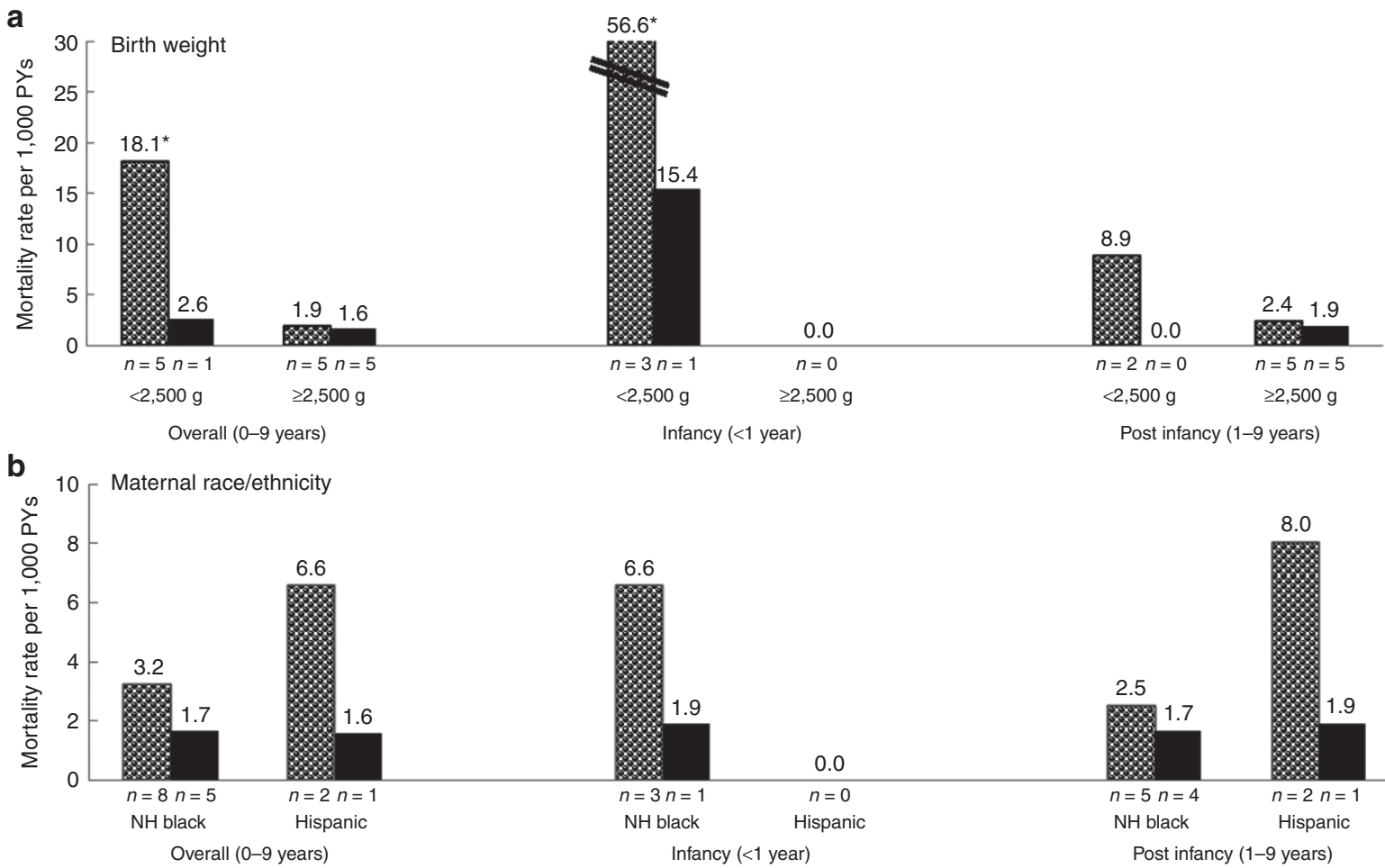

Infancy $(<1$ year $)$

Post infancy (1-9 years)
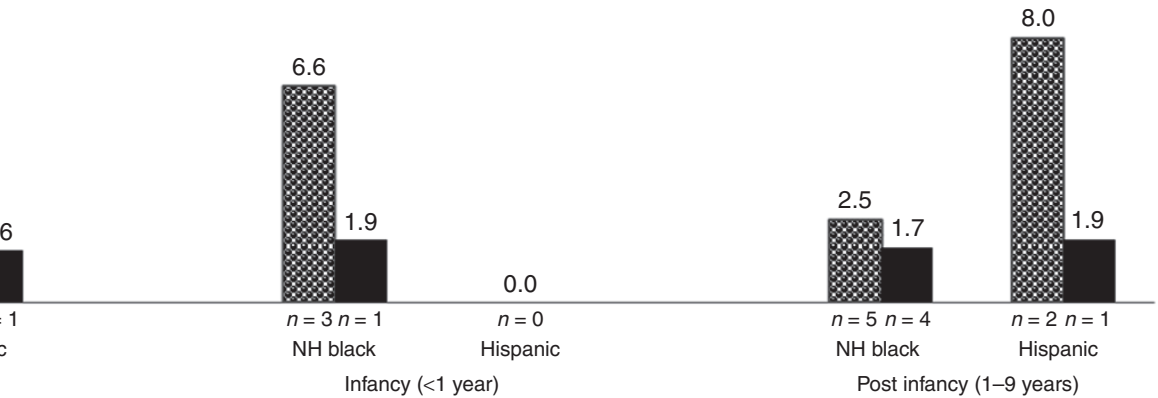

圈 US-born

Foreign-born

Figure 1 Comparison of mortality rate (per 1,000 person-years (PYs)) among New York children born in $2000-2008$ with $\mathrm{HbSS}$ or $\mathrm{HbS} \beta^{\circ}$ by maternal nativity (US born, foreign born) and age group (overall: 0-9 years; infancy: <1 year; post infancy: 1-9 years). Stratified by (a) birth weight $(<2,500 \mathrm{~g}$ or $\geq 2,500 \mathrm{~g})$ and $(\mathbf{b})$ maternal race/ethnicity (non-Hispanic $(\mathrm{NH})$ white, $\mathrm{NH}$ black, Hispanic). *A statistically significant difference was found between low birth weight and normal birth weight. $N$, number of deaths in each category; Zero rate, resulted from zero deaths. 
Table 3 Causes of death related to sickle cell disease (SCD) by SCD phenotype as recorded in death certificates (New York State Birth Cohort, 2000-2008)

\begin{tabular}{|c|c|c|c|c|c|c|}
\hline \multirow[b]{2}{*}{ Cause of death } & \multicolumn{2}{|c|}{ All SCD } & \multicolumn{2}{|c|}{$\mathrm{HbSS}$ or $\mathrm{HbS} \beta^{0}$} & \multicolumn{2}{|c|}{$\mathrm{HbSC}$} \\
\hline & Deaths & $\%$ & Deaths & $\%$ & Deaths & $\%$ \\
\hline Had ICD-10 codes $^{a}$ for SCD & 12 & 57.1 & 12 & 75.0 & 0 & 0.0 \\
\hline Related to SCD & 10 & 47.6 & 10 & 62.5 & 0 & 0.0 \\
\hline Not related to SCD & 2 & 9.5 & 2 & 12.5 & 0 & 0.0 \\
\hline Had no ICD-10 code for SCD & 9 & 42.9 & 4 & 25.0 & 5 & 100.0 \\
\hline Total & 21 & 100.0 & 16 & $76.2^{b}$ & 5 & $23.8^{\mathrm{b}}$ \\
\hline
\end{tabular}

$\mathrm{HbS} \beta^{\circ}$, sickle $\beta^{0}$ thalassemia; HbSC, sickle-hemoglobin C disease; HbSS, hemoglobin S disease.

${ }^{a}$ The 10 th revision of the International Classification of Diseases (ICD-10) codes for SCDs: D57.0 and D57.1 for HbSS; D57.2 for HbSC; D57.4 for HbS $\beta^{\circ}$ and HbS $\beta$; and D57.8 for other forms of SCD. ${ }^{b}$ Row percentage.

toddlers between 1 and $<2$ years old (3.3 per 1,000 personyears), with a median age at death of 17 months. A significant ninefold higher mortality rate was found among LBW infants as compared with those with normal birth weight (20.8 vs. 2.3 per 1,000 person-years; $P<0.01$ ); a smaller but nonsignificant difference in mortality was observed among toddlers. Similarly, statistically significant differences in mortality were observed among preterm children as compared with full-term children at ages 0 to $<2$ years ( 11.4 vs. 2.8 per 1,000 person-years; $P=0.02$ ) and among infants of US-born mothers versus foreign-born mothers ( 8.4 vs. 1.0 per 1,000 person-years; $P=0.03$ ). For the two maternal racial/ethnic groups examined, there was no significant difference in mortality rates among children younger than 2 years old. However, children ages 2-9 years born to Hispanic mothers had a significantly higher mortality rate as compared with those born to non-Hispanic black mothers (3.5 vs. 0.7 per 1,000 person-years; $P=0.05$ ).

As compared with all-cause mortality from 28 days through 9 years of age for all New York births (with or without SCD) during 2000-2008, mortality among children with SCD was significantly higher; the rate ratio was 3.6 for all SCD cases and 5.1 for HbSS or $\mathrm{HbS}^{0}$ cases (Table 2). Mortality rate ratios by age group were $1.5,10.0$, and 7.0 at 28 days to 11 months, 12-23 months, and 2-9 years, respectively. Postneonatal infant (28 days to 11 months) mortality rates were not significantly higher among children with SCD, but child ( $\geq 1$ year) mortality rates were significantly higher for children with SCD. By SCD type, child mortality ratios were significantly higher for HbSS or $\mathrm{HbS} \beta^{0}$ cases but not for HbSC cases.

Among children born to non-Hispanic black mothers, mortality from 28 days through 9 years was, significantly, 1.9 times higher for children with SCD as compared with all New York children (Table 2). Children with SCD born to Hispanic mothers had a significant 6.1-fold higher mortality rate as compared with all children of Hispanic mothers. Among children with $\mathrm{HbSS}$ or $\mathrm{HbS} \beta^{0}$ born to non-Hispanic black or Hispanic mothers, the mortality ratios were 2.7 and 8.4 , respectively, both of which were statistically significant.

LBW children with HbSS or HbS $\beta^{\circ}$ born to US-born mothers had a significant sevenfold higher overall mortality rate as compared with those of foreign-born mothers (18.1 vs. 2.6 per 1,000 person-years; $P=0.09$ ); the infant mortality rate was 3.7-fold (statistically nonsignificantly) higher (56.6 vs. 15.4 per 1,000 person-years; $P=0.33$ ) (Figure 1a). Among children with $\mathrm{HbSS}$ or $\mathrm{HbS} \beta^{0}$ born to US-born mothers, a statistically significant 9.5 -fold higher overall mortality rate was found among LBW $(<2,500 \mathrm{~g})$ children as compared with normal-birthweight children (18.1 vs. 1.9 per 1,000 person-years; $P<0.01$ ); infant mortality rates were 56.6 and 0.0 per 1,000 person-years, respectively $(P<0.01)$. No differences by maternal race/ethnicity stratified by maternal place of birth were significant (Figure 1b).

Twelve of the 21 deaths (57.1\%) had SCD listed on the death certificate, and all had HbSS or HbS $\beta^{\circ}$ based on NBS records (Table 3). Among the 12 deaths with SCD listed on the death certificate, 2 were likely unrelated to SCD; the cause in one case was listed as "noninfective gastroenteritis and colitis" and the other cause was listed as birth asphyxia and respiratory arrest. The remaining 10 deaths $(47.6 \%)$ were presumed to be related to SCD. Of those 10 deaths, 2 had no other cause listed, 4 had respiratory disorders, 2 had sepsis, and one each had spleen disease and heart disease listed.

Of the nine deaths (42.9\%) for which SCD was not mentioned on the death certificate, four had HbSS or $\mathrm{HbS}^{\circ}$ and five had HbSC (Table 3). The most common underlying causes were external injury $(\mathrm{n}=3)$ and extreme immaturity $(\mathrm{n}=2)$. The remaining four deaths had birth injury, noninfective gastroenteritis and colitis in combination with prematurity, congenital anomaly in combination with prematurity, and intussusception listed and were not classified as related to SCD. Of the 16 deaths among children with $\mathrm{HbSS}$ or $\mathrm{HbS} \beta^{0}, 10$ (62.5\%) were presumed related to SCD, as noted above. By contrast, all five deaths among children with HbSC appeared to be unrelated to SCD. Deaths unrelated to SCD accounted for 10 of 14 deaths among children with SCD during the first 2 years of life. None of the five deaths before 6 months of age were classified as related to SCD.

\section{DISCUSSION}

This study used linked NBS and vital (both birth and death) records to investigate childhood mortality for a statewide cohort of children with SCD followed from diagnosis after NBS for 1-10 years. One previous study from 1998 used linked NBS and death records to evaluate SCD-related mortality during the 
first 3 years of life in three states. ${ }^{32}$ Other studies either followed a birth cohort of children identified through NBS through a tertiary-care center ${ }^{12,14}$ or relied on death certificates to ascertain cases of SCD. ${ }^{11,13,15}$ The linkage with vital records also allowed assessment of the association of LBW with infant and child mortality among children diagnosed with SCD.

The low mortality rates among young children with SCD born during 2000-2008 in New York are consistent with published estimates of national trends in SCD-related pediatric mortality. ${ }^{13,15,16}$ Yanni et al. ${ }^{13}$ reported a roughly $40 \%$ decrease in SCD mortality among black children ages $0-3$ years between 19951998 and 1999-2002, although the International Classification of Diseases, 10th revision, codes used for the latter time period did not include codes for SCD- $\beta$ thalassemia. The investigators attributed the decrease in large part to the routine administration of pneumococcal conjugate vaccine beginning in 2000 . Similarly, Hamideh and Alvarez ${ }^{15}$ reported $>50 \%$ decreases in SCD mortality among African-American children $<1$ and 1-4 years of age between 1989-1998 and 1999-2003, although the earlier period included years before the introduction of universal NBS in a number of states. Lanzkron et al. ${ }^{16}$ reported a roughly one-third reduction in all-SCD mortality for AfricanAmerican children $<19$ years old between 1994-1998 and 1999-2005 but did not report estimates for younger children.

The Dallas Newborn Cohort, reflecting data for children followed at a single tertiary-care center, reported that all-cause mortality during the first 2 years of life (ages $<2$ years) for children with HbSS or HbS $\beta^{\circ}$ born in 2000-2007 and diagnosed following NBS was 3.2 per 1,000 person-years. ${ }^{14}$ In comparison, in the present New York statewide cohort study the allcause mortality rate for children ages 0 to $<2$ years with $\mathrm{HbSS}$ or $\mathrm{HbS} \beta^{0}$ born in 2000-2008 and diagnosed following NBS was 4.4 per 1,000 person-years, one-third higher. At ages 2-9 years, mortality rates were 0 (in the study using the Dallas cohort) and 1.4 per 1,000 person-years (in the study using the New York cohort). The absolute differences in mortality rates were 1.2 per 1,000 person-years during the first 2 years and 1.4 per 1,000 person-years at ages 2-9 years.

A previous study reported that among black infants born in California and Illinois during 1990-1994, 1.5\% of children with SCD diagnosed after NBS died of any cause by the end of 1995; the cumulative mortality rate for all black children born during the same time period was $2.0 \% .^{32}$ The present study likewise found that cumulative all-cause mortality was lower among children with confirmed SCD born to New York non-Hispanic black mothers than among all children born to New York non-Hispanic black mothers during the same time period (data not shown). However, when neonatal deaths were excluded to avoid bias from undercounting deaths among children with undiagnosed SCD, the results were reversed, and all-cause mortality was significantly higher for children with SCD born to non-Hispanic black mothers. In particular, deaths were substantially higher among children with HbSS or $\mathrm{HbS}^{\circ}$; among children with HbSC, deaths were not significantly increased relative to the general population matched by maternal race and ethnicity. The implication is that, overall, deaths in early childhood remain significantly higher among children with the more severe forms of SCD but not for children with the milder forms.

Twelve of 21 deaths among children identified with SCD through NBS in New York had SCD listed on the death certificate as an underlying cause of death. Ten of the $12(47.6 \%)$ were SCD-related deaths; all occurred among the $61 \%$ (1,173 of $1,911)$ of children who had sickle cell anemia (HbSS or HbS $\beta^{\circ}$ ). Children with HbSC or other forms of SCD and who died had causes of infant and child mortality similar to those of the general population. These results are similar to the findings of the Dallas Newborn Cohort study that 15 of 25 infant and child deaths (60\%) before 2002 were related to SCD, and all 15 of those children had HbSS. ${ }^{14}$

Infant mortality was significantly higher among New York children with diagnosed SCD born to US-born mothers as compared with those born to foreign-born mothers. That difference appears seems to be unrelated to SCD subtype and race/ ethnicity; no subgroup differences are statistically significant. Although not statistically significant, five of six deaths among children with $\mathrm{HbSS}$ or $\mathrm{HbS} \beta^{0}$ who had a birth weight $<2,500 \mathrm{~g}$ occurred among children of US-born mothers (Table 1). This could reflect the so-called immigrant paradox that black or Hispanic children born to US-born mothers are at higher risk for LBW than babies born to foreign-born mothers. ${ }^{33,34} \mathrm{~A}$ study from Florida reported that children with SCD were roughly $50 \%$ more likely to have a birth weight of $<2,500 \mathrm{~g}$ and roughly $200 \%$ more likely to have a birth weight of $<1,500 \mathrm{~g} .{ }^{35}$ Children with SCD and US-born mothers may be at the greatest risk for lethal complications of LBW.

Estimates of mortality among children with diagnosed SCD do not capture deaths among infants born with SCD who die before diagnosis. Three neonatal deaths were recorded among 1,911 infants with a diagnosis of SCD, but 13-17 deaths would be expected, using the average neonatal mortality rates of 7 or 8.8 per 1,000 births recorded for infants born to nonwhite or black mothers in the United States during 2006, respectively. ${ }^{36}$ Thus, the true number of infants born with SCD in New York during the study period may have been 1,921 to 1,925 , with $0.5-0.7 \%$ missed cases as a result of death before diagnosis.

The exclusion of neonatal deaths occurring before diagnosis following NBS has broader ramifications for studies of outcomes for conditions following NBS. Restricting cases to children with a confirmed diagnosis excludes infants with the disorder who died before they could complete the screening and diagnostic process. No NBS test should be assumed to detect $100 \%$ of cases, and children who die as neonates are susceptible to not being counted among confirmed cases of disease. ${ }^{37}$

This study has limitations similar to those of the 1998 three-state study ${ }^{32}$ and other state-specific analyses of survival. First, deaths that occurred outside of New York are not recorded in New York death records. However, a recent study of early childhood mortality and survival among Texas children with selected birth defects reported that using the 
National Death Index, which includes all US deaths, to supplement the Texas state death certificates identified only 0.7 and $1.5 \%$ additional deaths among children with congenital heart defects ${ }^{38}$ and children with heterotaxy syndrome, ${ }^{39}$ respectively. Second, the inability to link some records to death certificates could have resulted in some deaths being missed. Third, SCD-related complications may not be recorded on death certificates, and the assignment of deaths as SCD related or unrelated is subjective. Fourth, because births without a SCD diagnosis were not linked to death records, we were not able to compare mortality for children without SCD with that for children with SCD. Fifth, some of the stratified analyses in our study have unstable results because of small numbers, and those findings need to be interpreted with caution. Sixth, because of small numbers of deaths, we were not able to control for potential confounding through multivariable analysis. Nonetheless, important study strengths are the validated diagnoses of SCD and population-based data that provide more comprehensive representativeness of outcomes compared with clinic-based studies.

In summary, this statewide population assessment of children in New York affected by SCD and born since 2000 indicates that postneonatal (28 days to 9 years) mortality for children with $\mathrm{HbSS}$ or $\mathrm{HbS}^{0}$ remains significantly higher than that for all children of the same ages born in New York matched by maternal race/ethnicity. Despite recent progress in reducing mortality among young children with $\mathrm{SCD},{ }^{13-16}$ some children with sickle cell anemia ( $\mathrm{HbSS}$ or $\mathrm{HbS}^{\circ}$ ) continue to die of complications of SCD..$^{40}$ To fully realize the promise of NBS in preserving lives of children affected by SCD, health strategies must increase the promotion of evidence-based disease-modifying therapies, comprehensive regular screening for disease-related complications, and parental education; LTFU is needed to assess the use of services and outcomes.

\section{ACKNOWLEDGMENTS}

This project was supported by the US Centers for Disease Control and Prevention and the National Heart, Lung and Blood Institute (grant U50DD000722). The findings and conclusions in this report are those of the authors and do not necessarily represent the official position of the Centers for Disease Control and Prevention.

\section{DISCLOSURE}

The authors declare no conflict of interest.

\section{REFERENCES}

1. Brousseau DC, Panepinto JA, Nimmer M, Hoffmann RG. The number of people with sickle-cell disease in the United States: national and state estimates. Am J Hematol 2010;85:77-78.

2. Hassell KL. Population estimates of sickle cell disease in the U.S. Am J Prev Med 2010;38(suppl 4):S512-S521.

3. Siddiqui S, Schunk K, Batista M, et al. Awareness of sickle cell among people of reproductive age: Dominicans and African Americans in northern Manhattan. J Urban Health 2012;89:53-58.

4. Frenette PS, Atweh GF. Sickle cell disease: old discoveries, new concepts, and future promise. J Clin Invest 2007;117:850-858.
5. Wang $Y$, Kennedy J, Caggana $\mathrm{M}$, et al. Sickle cell disease incidence among newborns in New York State by maternal race/ethnicity and nativity. Genet Med 2013;15:222-228.

6. Darbari DS, Panepinto JA. What is the evidence that hydroxyurea improves health-related quality of life in patients with sickle cell disease? Hematology Am Soc Hematol Educ Program 2012;2012:290-291.

7. Leikin SL, Gallagher D, Kinney TR, Sloane D, Klug P, Rida W. Mortality in children and adolescents with sickle cell disease. Cooperative Study of Sickle Cell Disease. Pediatrics 1989;84:500-508.

8. Scott RB. Health care priority and sickle cell anemia. JAMA 1970; 214:731-734.

9. Platt OS, Brambilla DJ, Rosse WF, et al. Mortality in sickle cell disease. Life expectancy and risk factors for early death. N Eng/ J Med 1994;330:1639-1644.

10. Gill FM, Sleeper LA, Weiner SJ, et al. Clinical events in the first decade in a cohort of infants with sickle cell disease. Cooperative Study of Sickle Cell Disease. Blood 1995;86:776-783.

11. Davis H, Schoendorf KC, Gergen PJ, Moore RM Jr. National trends in the mortality of children with sickle cell disease, 1968 through 1992. Am J Public Health 1997;87:1317-1322.

12. Quinn $C T$, Rogers $Z R$, Buchanan GR. Survival of children with sickle cell disease. Blood 2004; 103:4023-4027.

13. Yanni E, Grosse SD, Yang Q, Olney RS. Trends in pediatric sickle cell diseaserelated mortality in the United States, 1983-2002.J Pediatr 2009;154:541-545.

14. Quinn CT, Rogers ZR, McCavit TL, Buchanan GR. Improved survival of children and adolescents with sickle cell disease. Blood 2010;115:3447-3452.

15. Hamideh $D$, Alvarez $O$. Sickle cell disease related mortality in the United States (1999-2009). Pediatr Blood Cancer 2013;60:1482-1486.

16. Lanzkron S, Carroll CP, Haywood C Jr. Mortality rates and age at death from sickle cell disease: U.S., 1979-2005. Public Health Rep 2013;128:110-116.

17. Vichinsky E, Hurst D, Earles A, Kleman K, Lubin B. Newborn screening for sickle cell disease: effect on mortality. Pediatrics 1988;81:749-755.

18. Frempong T, Pearson HA. Newborn screening coupled with comprehensive follow-up reduced early mortality of sickle cell disease in Connecticut. Conn Med 2007:71:9-12.

19. Benson JM, Therrell BL Jr. History and current status of newborn screening for hemoglobinopathies. Semin Perinatol 2010;34:134-144.

20. American Academy of Pediatrics. Section on Hematology/Oncology Committee on Genetics. Health supervision for children with sickle cell disease. Pediatrics 2002;109:526-535

21. Gaston MH, Verter Jl, Woods $\mathrm{G}$, et al. Prophylaxis with oral penicillin in children with sickle cell anemia. A randomized trial. N Engl J Med 1986;314:1593-1599.

22. Charache S, Terrin ML, Moore RD, et al. Effect of hydroxyurea on the frequency of painful crises in sickle cell anemia. Investigators of the Multicenter Study of Hydroxyurea in Sickle Cell Anemia. N Engl J Med 1995;332:1317-1322.

23. Steinberg MH, McCarthy WF, Castro O, et al.; Investigators of the Multicenter Study of Hydroxyurea in Sickle Cell Anemia and MSH Patients' Follow-Up. The risks and benefits of long-term use of hydroxyurea in sickle cell anemia: a 17.5 year follow-up. Am J Hematol 2010;85:403-408.

24. Wang WC, Ware RE, Miller ST, et al.; BABY HUG investigators. Hydroxycarbamide in very young children with sickle-cell anaemia: a multicentre, randomised, controlled trial (BABY HUG). Lancet 2011;377:1663-1672.

25. Adamkiewicz TV, Silk BJ, Howgate J, et al. Effectiveness of the 7-valent pneumococcal conjugate vaccine in children with sickle cell disease in the first decade of life. Pediatrics 2008:121:562-569.

26. Kemper AR, Boyle CA, Aceves J, et al. Long-term follow-up after diagnosis resulting from newborn screening: statement of the US Secretary of Health and Human Services' Advisory Committee on Heritable Disorders and Genetic Diseases in Newborns and Children. Genet Med 2008;10:259-261.

27. Hinton CF, Mai CT, Nabukera SK, et al. Developing a public health-tracking system for follow-up of newborn screening metabolic conditions: a four-state pilot project structure and initial findings. Genet Med 2014;16:484-490.

28. Wang Y, Caggana M, Sango-Jordan M, Sun M, Druschel CM. Long-term follow-up of children with confirmed newborn screening disorders using record linkage. Genet Med 2011;13:881-886.

29. Wang Y, Sango-Jordan M, Caggana M. Acute care utilization for inherited metabolic diseases among children identified through newborn screening in New York state. Genet Med 2014;16:665-670.

30. Hemoglobinopathy Monitoring. Centers for Disease Control and Prevention. http://www.cdc.gov/ncbddd/hemoglobinopathies/index.html. Accessed 1 May, 2014

31. Newborn Screening Program, New York State Department of Health. Annual Reports. Online publications. http://www.wadsworth.org/newborn/annualrept/ annsum.htm. Accessed 1 May, 2014 
32. Centers for Disease Control and Prevention (CDC). Mortality among children with sickle cell disease identified by newborn screening during 1990-1994 -California, Illinois, and New York. MMWR Morb Mortal Wkly Rep 1998;47:169172.

33. Urquia ML, Glazier RH, Blondel B, et al.; ROAM collaboration. International migration and adverse birth outcomes: role of ethnicity, region of origin and destination. J Epidemiol Community Health 2010;64: 243-251.

34. Vang ZM, Elo IT. Exploring the health consequences of majority-minority neighborhoods: minority diversity and birthweight among native-born and foreign-born blacks. Soc Sci Med 2013;97:56-65.

35. Whiteman V, Salinas A, Weldeselasse HE, et al. Impact of sickle cell disease and thalassemias in infants on birth outcomes. Eur J Obstet Gynecol Reprod Biol 2013;170:324-328.
36. Heron M, Hoyert DL, Murphy SL, Xu J, Kochanek KD, Tejada-Vera B. Deaths: final data for 2006. Nat/ Vital Stat Rep 2009;57:1-134.

37. Grosse SD, Sarafoglou K. Does newborn screening have $100 \%$ sensitivity to detect salt-wasting CAH? A word of caution. JAMA Pediatrics, in press.

38. Nembhard WN, Salemi JL, Ethen MK, Fixler DE, Dimaggio A, Canfield MA. Racial/Ethnic disparities in risk of early childhood mortality among children with congenital heart defects. Pediatrics 2011;127:e1128-e1138.

39. Marengo LK, Hoyt AT, Canfield MA. The utility of the National Death Index as a supplemental data source in ascertaining 5 -year mortality among Texas heterotaxy cases. J Registry Manag 2014;41:4-6.

40. Payne AB, Link-Gelles R, Azonobi I, et al.; Active Bacterial Core Surveillance Team. Invasive pneumococcal disease among children with and without sickle cell disease in the United States, 1998 to 2009. Pediatr Infect Dis J 2013;32:1308-1312. 